\title{
Control of an Independent 4WD electric vehicle by DYC method
}

\author{
Husain Kanchwala* \\ Department of Mechanical Engineering, \\ Indian Institute of Technology, \\ Kanpur, India \\ E-mail: husain.talk@gmail.com \\ *Corresponding author
}

\section{Johan Wideberg, Carlos Bordons Alba and David Marcos}

\author{
Ingenieria de los Transportes, \\ Universidad de Sevilla, \\ Sevilla, Spain \\ E-mail: johanw@gmail.com \\ E-mail: bordons@us.es \\ E-mail: dmarcos@us.es
}

\begin{abstract}
Current advances in the application of control systems to vehicle dynamics has made it practicable to improve the vehicle's longitudinal, lateral and vertical dynamics. Some of the examples of application of these systems to vehicle control are traction control (longitudinal dynamics) to prevent wheel slip, ESP (lateral dynamics) to prevent loss of stability, and active suspension (vertical dynamics) to increase ride comfort. In this paper, the vehicle lateral motion is controlled by direct yaw control (DYC) method. This uses the yaw moment produced by the longitudinal forces of the tyres, for stabilising the vehicle motion during critical cornering conditions. The system is been designed to give substantially enhanced active safety and dynamic handling control. The vehicle dynamics control algorithm is developed for a FOX vehicle by controlling couple traction/braking torque of the four in-wheel motors, from basic driving slogans. These are the steering angle, position of the accelerator pedal and brake by the position of the brake pedal, as shown in Figure 1.
\end{abstract}

Keywords: vehicle dynamics; direct yaw control; DYC; simulation; handling; torque vectoring; $4 \mathrm{WD}$; EV.

Reference to this paper should be made as follows: Kanchwala, H., Wideberg, J., Alba, C.B. and Marcos, D. (xxxx) 'Control of an Independent 4WD electric vehicle by DYC method', Int. J. Vehicle Systems Modelling and Testing, Vol. X, No. Y, pp.xxx-xxx.

Biographical notes: Husain Kanchwala is a $\mathrm{PhD}$ scholar at Indian Institute of Technology, Kanpur. He is been working in the field of vehicle dynamics and control, ride comfort and suspension design optimisation. He has been associated with the development of ITS for Toyota COMS, a project funded by Waseda University, Japan. He is currently working in the field of vehicle 
control by torque vectoring in University of Seville under Erasmus Mundus Program. Before joining for $\mathrm{PhD}$, he had worked in multi body dynamics domain in Mahindra \& Mahindra in Drive Away Chassis (DAC) Vehicle Dynamics Group as an Assistant Manager.

Johan Wideberg is a Professor in Transportation Engineering at the School of Engineering at the University of Seville. Since 1999, he teaches courses in the subject areas of vehicle technology and transportation engineering. His research focus is on vehicle dynamics and transportation engineering with an emphasis on ITS. He is also involved as expert evaluator for research programmes at both national and EU level. Apart from teaching and research, he also serves as the Deputy Director of External Relations at the engineering school and the member of the board for the company chairs of EADS and CEPSA at the university as well as responsible for the T.I.M.E network.

Carlos Bordons Alba is a Professor of Automation and System Engineering. He teaches control engineering, predictive control methodologies and systems theory. He has varied research interests and has been working on a number of projects like control of energy systems, control of fuel cell systems, implementation of predictive controllers, industrial process control, modelling and simulation and supervisory control.

David Marcos is a PhD scholar in Universidad de Seville, Spain. He is been working in the field of electric vehicles. His $\mathrm{PhD}$ research is based on energy management of electric drives and electric motor control.

\section{Introduction}

Direct yaw control (DYC) is the one of the modern active safety assist system introduced to control vehicle directional stability. At high values of lateral acceleration tyre force approaches the adhesion limit and the vehicle side-slip angle grows. As vehicle slips, the steering is no more capable of generating yaw moment. This is discussed by Shibahata et al. (1993).

The vehicle becomes laterally unstable because of this decrease in yaw moment at high side slip. Significant amount of research has been done to generate a restoring moment by differential braking also known as ESC (van Zanten et al., 1998; Wang and Longoria, 2006) and four wheel steering (Abe, 1999; Selby et al., 2001). With the advent of electric motor drives it became easy to directly control the torque given in the four wheels to generate the yaw moment because of unequal torques. Generally, the vehicle yaw rate and side-slip angle are chosen as the control variables. DYC methods have been proposed by choosing either of them or both of them. The yaw rate control by DYC has been implemented by Esmailzadeh et al., 2003; Mirzaei et al., 2008; Mokhiamar and Abe, 2002). Researchers who have discussed side-slip control by DYC are Abe (1999), Abe

et al. (2001) and Eslamian et al. (2007). Literature is available in which DYC is implemented where both the variables have been simultaneously controlled by DYC (Zheng et al., 2006; Park et al., 2001; Gutiérrez et al., 2011). Some research is been done to develop unified chassis controllers which simultaneously control a number of vehicle 
characteristics like roll, pitch, etc. in addition to the above discussed control variables (Yoon et al., 2010; Kang et al., 2011).

The research done in the field of vehicle control employs various control theories like optimal control (Yamakawa and Watanabe, 2006), model predictive control (Mirzaei et al., 2008), fuzzy control (Tahami et al., 2004), LQ control (Park et al., 2001), etc.

This is been widely seen that so far most of the research lacks to obtain well defined closed form solutions of vehicle behaviour for a pre-defined value of side slip and desired yaw rate. We have focused to obtain a closed form solution of a desired value of yaw rate and zero side slip angle by using DYC method.

The proposed control methodology is shown in Figure 1.

Figure 1 Vehicle dynamics control, proposed structure (see online version for colours)

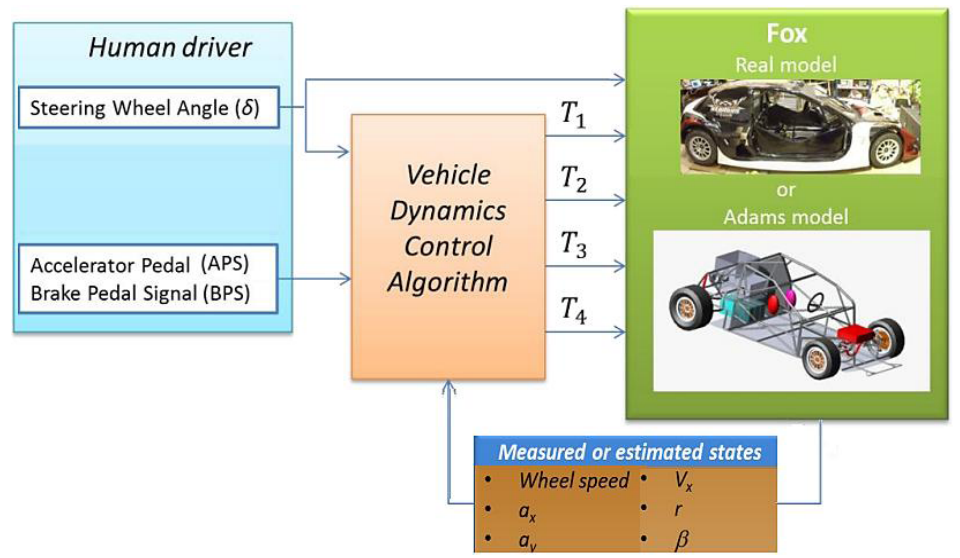

\section{Background}

The vehicle used for study is a FOX vehicle equipped with in-hub electric motors. The total torque output of the battery is fixed and it is to be distributed among four in-hub wheel motors such that the vehicle side slip is zero at all point of time as it is an undesirable characteristic resulting in loss of control and confidence level of the driver. Also, a desired value yaw rate is maintained. Total torque is distributed by means of three drive ratios namely,

$1 K_{f r}=$ front to rear drive ratio

$2 \quad K_{f l r}=$ front left to right drive ratio

$3 K_{r l r}=$ rear left to right drive ratio.

In this paper, we have used scalar equations. It is desirable to express these without introducing the heading angle therefore 'vehicle fix coordinates' are used. The road is considered to be flat hence only planar motion is been studied also vehicle roll is neglected.

The mathematical model is been developed for a very generic load case and is applicable for either accelerating/de-accelerating vehicle under cornering. The effect of 
load transfer on tyre cornering stiffness has also been considered in this study (Abe, 2009).

An algorithm is developed using vehicle dynamics equations and PID controller coupled with the MBD vehicle model built up in ADAMS car (MSC Software, 2013). The Simulink model of the controller is then integrated with the vehicle model and a co-simulation study is been performed. The vehicle is subjected to a standard ISO 3888 double lane change (DLC) handling manoeuvre. The model further validated with field tests performed at the testing facility in Universidad de Sevilla. The methodology of the procedure discussed above is shown by a flow chart in Figure 2.

Figure 2 DYC process flow chart

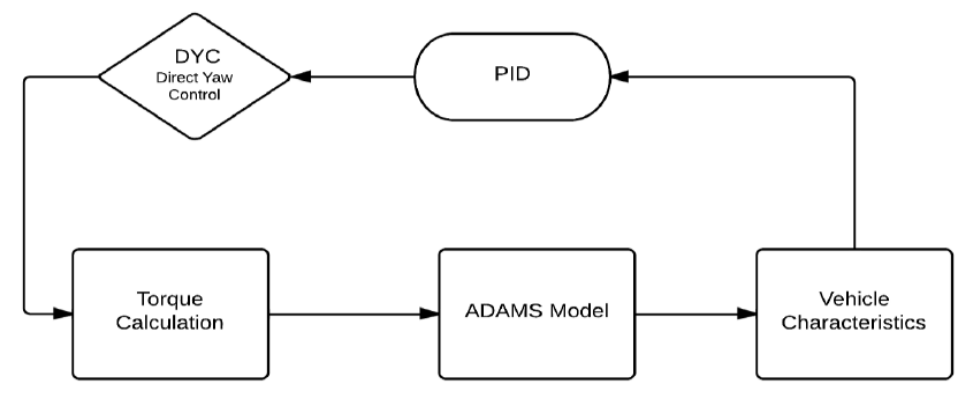

\section{Mathematical model}

The cornering lateral acceleration of a vehicle with weight $W$, when accompanied by traction/braking, is defined as $\ddot{y}$. The equations of motion are given by (Rajamani, 2006):

$$
\begin{aligned}
& W \ddot{y}=\left(K_{f 1}+K_{f 2}\right) \beta_{f}+\left(K_{r 1}+K_{r 2}\right) \beta_{r} \\
& l_{f}\left(K_{f 1}+K_{f 2}\right) \beta_{f}-l_{r}\left(K_{r 1}+K_{r 2}\right) \beta_{r}=0
\end{aligned}
$$

The tyre cornering stiffness depends on the load on the tyre. We have considered the effect of the load transfer on cornering stiffness up to first order term. If longitudinal force, (traction/braking) is acting on the tyre, the maximum cornering force, for a large side-slip angle, is

$$
F_{\max }=\sqrt{\mu^{2} W^{2}-T^{2}}
$$

If the traction/braking force is small compared to the tyre load, the cornering stiffness at small side-slip angle, could be written as below:

$$
K_{f 1} \approx\left\{K_{f 0}+\frac{\partial K_{f}}{\partial W}\left(-\Delta W_{f}-\frac{\Delta W}{2}\right)\right\}\left\{1-\frac{1}{2}\left(\frac{2 X_{f}}{\mu W_{f}}\right)^{2}\right\}
$$

where $\Delta W_{f}$ is the load transfer is across the front axle during cornering, $\Delta W$ is the load transfer between the front and rear due to traction/braking. By ignoring small terms and 
summing up left, right wheel cornering stiffnesses we get the equivalent cornering stiffness,

$$
\begin{aligned}
& 2 K_{f}^{*}=K_{f 1}+K_{f 2} \approx 2 K_{f 0}\left\{1-\frac{\partial K_{f}}{\partial W}\left(\frac{\Delta W}{2 K_{f 0}}\right)-\frac{1}{2}\left(\frac{2 X_{f}}{\mu W_{f}}\right)^{2}\right\} \\
& 2 K_{r}^{*}=K_{r 1}+K_{r 2} \approx 2 K_{r 0}\left\{1+\frac{\partial K_{r}}{\partial W}\left(\frac{\Delta W}{2 K_{r 0}}\right)-\frac{1}{2}\left(\frac{2 X_{r}}{\mu W_{r}}\right)^{2}\right\}
\end{aligned}
$$

where

$$
\begin{aligned}
& X_{f}=\text { Drive force front }=K_{f r} W a_{x} / 2 \\
& X_{r}=\text { Drive force rear }=\left(1-K_{f r}\right) W a_{x} / 2 \\
& \Delta W=h W a_{x} / l \\
& \frac{\partial K_{f / r}}{\partial W}=\text { Rate of change of front/rear cornering stiffness with vertical load }
\end{aligned}
$$

Expressing the equivalent cornering stiffnesses in terms of longitudinal acceleration $\ddot{x}$,

$$
\begin{aligned}
& 2 K_{f}^{*} \approx 2 K_{f 0}\left\{1+\frac{\partial K_{f}}{\partial W}\left(\frac{h W}{2 l K_{f 0}}\right) \ddot{x}-\frac{1}{2}\left(\frac{K_{f r} l}{\mu l_{r}}\right)^{2} \ddot{x}^{2}\right\} \\
& 2 K_{r}^{*} \approx 2 K_{r 0}\left\{1+\frac{\partial K_{r}}{\partial W}\left(\frac{h W}{2 l K_{r 0}}\right) \ddot{x}-\frac{1}{2}\left(\frac{\left(1-K_{f r}\right) l}{\mu l_{f}}\right)^{2} \ddot{x}^{2}\right\}
\end{aligned}
$$

The nominal cornering stiffness and the rate of change of stiffness with vertical load is been obtained using tyre data and fitting tool in ADAMS Car. The elastic deformation of a tyre is extremely complex due to the nonlinearity involved. There are several nonlinear tyre models available, e.g., the CALSPAN model (Kortüm, 1993), the brush model, etc. However, industry and academia have reached apparent consensus in recent years on the use of 'magic formula', developed by Pacejka (2002), which summarises experimental and theoretical data and allows high precision computation. PAC 2002 tyre model is used and basic tyre properties are obtained from the tyre manufacturer AVON (2013). The tyre governing equations are,

$$
\begin{aligned}
& y(x)=D \sin (C \arctan (B x-E(B x-\arctan B x))) \\
& Y(X)=y(x)+S_{v} ; x=X+S_{h}
\end{aligned}
$$

where $B$ is stiffness factor (controls slope of curve at origin), $C$ is shape factor (limits range of arguments in the sin function), $D$ is the maximum value of force/moment. The product $B C D$ gives the slope and corresponds to initial cornering stiffness. $S_{v}$ and $S_{h}$ are shift terms (for non-zero force/moments at zero slip). After plugging in the basic tyre properties, the tyre toolkit is used to obtain nominal cornering stiffness, i.e., at static load of FAW/2 and RAW/2 for front/rear tyre. Rate of change of stiffness with vertical load is obtained at zero slip angles. 
The values came out to be:

$$
\begin{array}{lll}
K_{f 0}=44,407.5 \mathrm{~N} / \mathrm{rad} ; & K_{r 0}=51,570 \mathrm{~N} / \mathrm{rad} \\
\frac{\partial K_{f}}{\partial W}=1.43 \mathrm{rad}^{-1} ; & \frac{\partial K_{f}}{\partial W}=1.432 \mathrm{rad}^{-1}
\end{array}
$$

Consider a cornering vehicle as shown in Figure 3. Because of difference in torque in left and right wheels there would be a difference in the rotational speeds (Spentzas and Alkhazali, 2001) and thus, the longitudinal slips of the left and right tyres are given by,

$$
\alpha_{l}=\frac{V-\frac{d}{2} \Omega-R_{0}\left(\omega-\frac{\Delta \omega}{2}\right)}{V-\frac{d}{2} \Omega} \approx \frac{-d \Omega+R_{0} \Delta \omega}{2 V}
$$

Similarly,

$$
\alpha_{r}=\frac{V+\frac{d}{2} \Omega-R_{0}\left(\omega+\frac{\Delta \omega}{2}\right)}{V+\frac{d}{2} \Omega} \approx \frac{d \Omega-R_{0} \Delta \omega}{2 V}
$$

The tractive force is given by,

$$
X_{L}=K_{\alpha} \alpha_{l} \text { and } X_{R}=K_{\alpha} \alpha_{R}
$$

Figure 3 Vehicle during combined cornering and traction

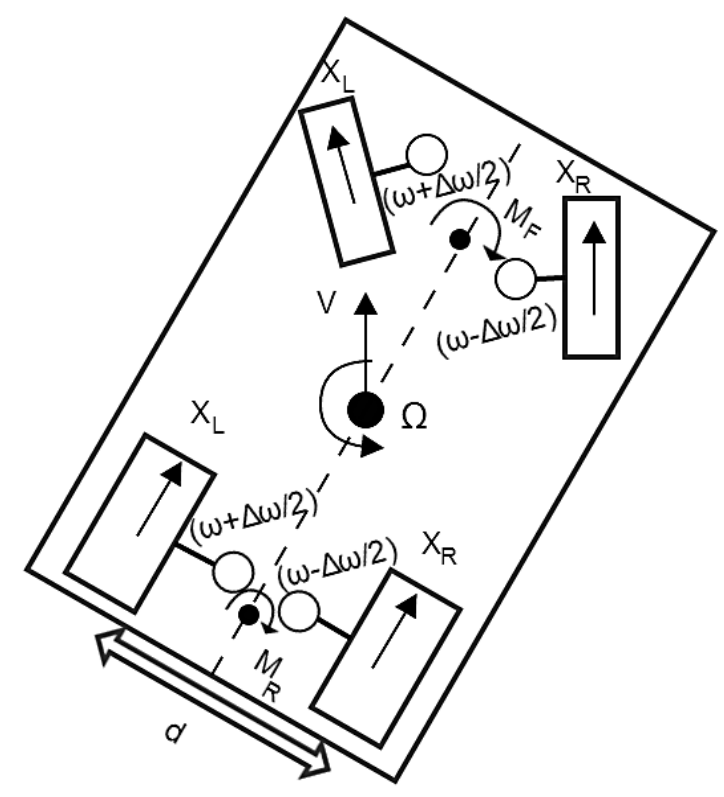


The yaw moment exerted on the vehicle is given by:

$$
M=\frac{-d}{2} X_{L}+\frac{d}{2} X_{R}
$$

Substituting equations (13) to (15) in (16) and simplifying we get,

$$
M=K_{\Omega} \frac{\Omega}{V}
$$

here $K_{\Omega}=$ Yaw moment coefficient.

The equations of vehicle motion with the additional yaw moment are described by,

$$
\begin{aligned}
& m V \frac{d \beta}{d t}+2\left(K_{f}+K_{r}\right) \beta+\left\{m V+\frac{2}{V}\left(l_{f} K_{f}-l_{r} K_{r}\right)\right\} \Omega=2 K_{f} \frac{\delta}{n} \\
& I_{z} \frac{d \Omega}{d t}+2\left(l_{f} K_{f}-l_{r} K_{r}\right) \beta+\left\{\frac{2}{V}\left(l_{f}^{2} K_{f}+l_{r}^{2} K_{r}\right)+\frac{K_{\Omega}}{V}\right\} \Omega=2 l_{f} K_{f} \frac{\delta}{n}
\end{aligned}
$$

It is desirable to obtain zero side slip. The possibility of having zero side-slip motion by $\mathrm{DYC}$ is investigated by giving different torques on all the four wheels so as to generate a yaw moment opposite to that of generated by lateral forces acting on the vehicle.

Figure 4 Vehicle bicycle model during combined cornering and traction

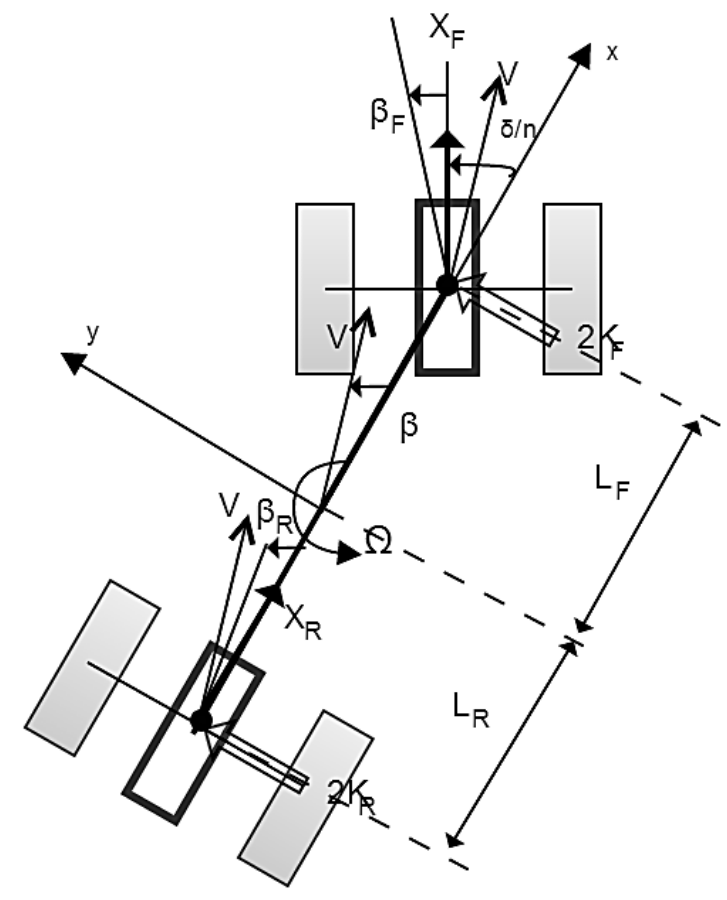


Under steady state condition,

$$
\frac{d \Omega}{d t}, \frac{d \beta}{d t}=0
$$

And for zero side slip angle, $\beta=0$ thus solving equation (17), (18) we get,

$$
K_{\Omega}=\frac{22_{r} K_{r}}{V}\left(1-\frac{m l_{f} V^{2}}{2 l l_{r} K_{r}}\right)
$$

Now, $M=M_{F}+M_{R}$.

Also, moment generated by front and rear axles should be equal, therefore,

$$
M_{F}=\frac{M}{2}=\frac{K_{\Omega} \Omega}{2 V}=-\frac{2 T K_{f r} K_{f l r}}{2 R_{w f}}+\frac{d T K_{f r}\left(1-K_{f l r}\right)}{2 R_{w f}}
$$

Therefore,

$$
K_{f l r}=\frac{1}{2}\left(\frac{1-K_{\Omega} \Omega R_{w f}}{d T V K_{f r}}\right)
$$

Similarly,

$$
K_{r l r}=\frac{1}{2}\left(\frac{1-K_{\Omega} \Omega R_{w r}}{d T V\left(1-K_{f r}\right)}\right)
$$

So far two ratios namely, $K_{f l r}$ and $K_{r l r}$ are determined but they in turn depend upon $K_{f r}$.

While vehicle is moving in a straight line, the front to rear torque split, $K_{f r}$ of $50 \%-50 \%$ is used. As the vehicle undergoes a turn, the difference between desired yaw rate from mathematical model and the observed yaw rate obtained from ADAMS model is calculated.

This difference is the error signal which is fed into a PID controller. The controller attempts to minimise the error by tuning the value of $K_{f r}$ which is in-turn fed back to the DYC model.

By substituting equation (20) in (18), we obtain the Desired Yaw rate as,

$$
\Omega_{\text {desired }}=\frac{2 K_{f}^{*} V \delta / n}{m V^{2}+2\left(l_{f} K_{f}^{*}-l_{r} K_{r}^{*}\right)}
$$

\section{Vehicle model}

FOX vehicle is mounted on the chassis of a racing car Silver Car S2. The chassis is been slightly modified for the placement of the new devices (batteries, etc.). Also, traditional suspension components are replaced with custom-made ones to accommodate wheel motors.

The vehicle is powered by means of four brushless DC wheel motors of $7 \mathrm{~kW}$ each driven by six battery modules LiFeMnPO4 of $12.8 \mathrm{~V}$ and $100 \mathrm{Ah}$ connected in series.

Vehicle model capable of simulating the dynamic behaviour of the vehicle has been developed in MSC ADAMS ${ }^{\circledR}$, a mechanical system dynamics simulation tool. Vehicle 
CAD model is prepared using the SolidWorks ${ }^{\circledR}$, from three-dimensional design of the chassis, provided by the manufacturer. This model is then imported in ADAMS to get precise suspension mounting locations. The kinematic configuration of the model consists of:

- 40 bodies

- 15 revolute joints

- 16 ball or spherical joints

- three translational joints

- four constant velocity (CV) joints

- 14 degree of freedom (DOF).

Figure 5 FOX vehicle with custom-made suspension components and in-hub wheel motors (see online version for colours)

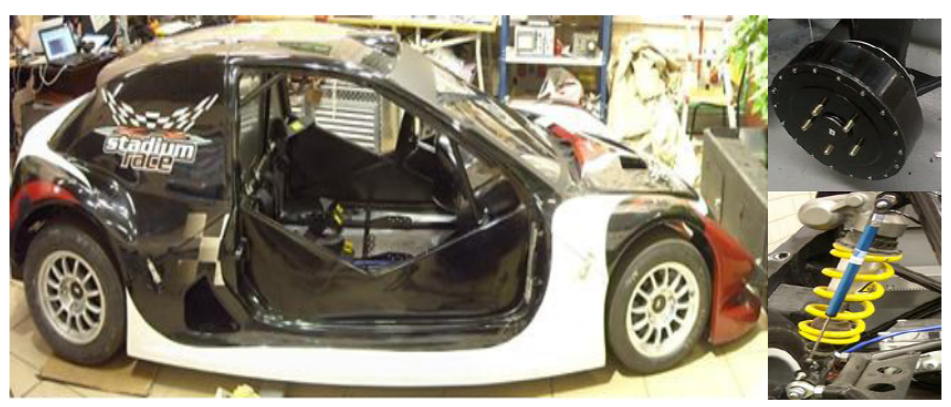

Figure 6 ADAMS-Car model of FOX vehicle (see online version for colours)

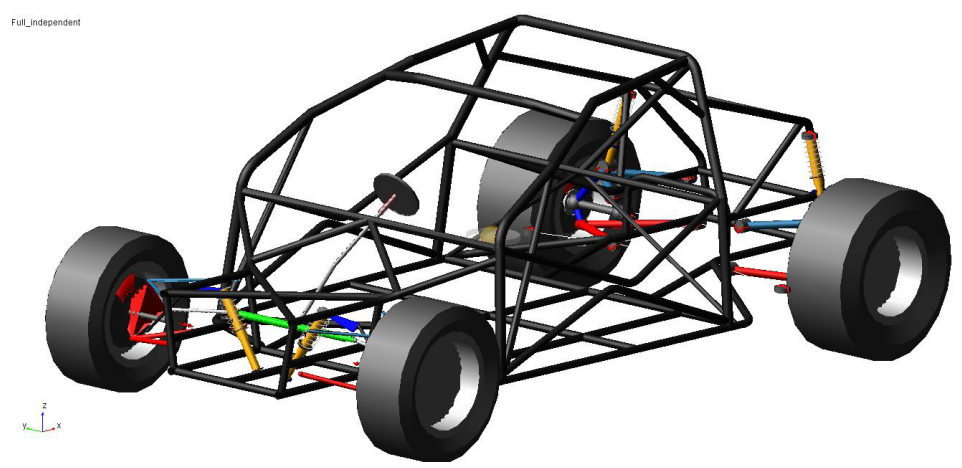

The vehicle has double wishbone front suspension, also called as deformable parallelogram arrangement, with elastic (spring) and dissipative (telescopic hydraulic damper) elements driven by bi-articulated rods and bell crank lever. The rear suspension comprises of two arms, hinged to the frame. The upper arm is connected by a spring-shock assembly to the frame. 
Figure 7 Half car front and rear suspension ADAMS-Car models of FOX vehicle (see online version for colours)

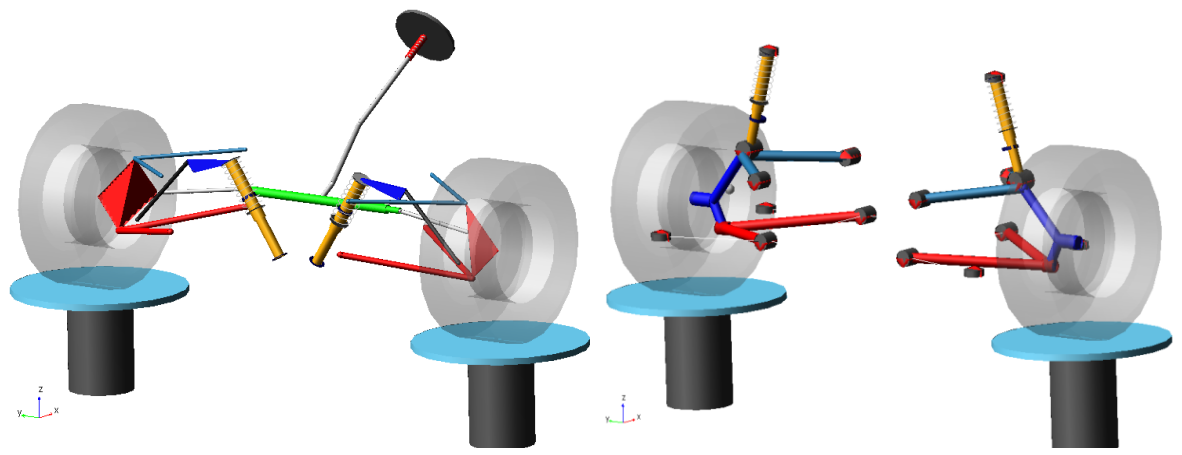

The springs and dampers are considered linear in the normal working range. The dynamic characteristics of the suspension assembly were initially unknown. These are determined in titration steps by performing wheel travel study on ADAMS half car models shown above.

\section{Controller model}

The mechatronics plug-in is used to integrate the control system model in Simulink with the ADAMS-CAR vehicle model. Four wheel torques are built up as state variables which act as actuators in the controls model and six transducer signals have been built as control inputs.

Table 1 ADAMS mechatronics control system input-output signals

\begin{tabular}{ll}
\hline Input & Output \\
\hline Yaw rate & Torque_FL \\
Lateral acceleration & Torque_FR \\
Velocity & Torque_RL \\
Steering angle & Torque_RR \\
Longitudinal acceleration & \\
Side slip angle & \\
\hline
\end{tabular}

For the realisation of DYC, the vehicle model is imported as an S-function block in Simulink and is then integrated with the torque calculation algorithm and PID controller. An interactive co-simulation is then run in which the wheel torques from the Simulink interface at each time step of $0.001 \mathrm{sec}$ is fed to the ADAMS-Car interface and the vehicle characteristics are in-turn fed back to Simulink for re-calculating wheel torques for the next time step.

Figure 8 shows the co-simulation interface. 
Figure 8 ADAMS - Simulink co-simulation interface (see online version for colours)

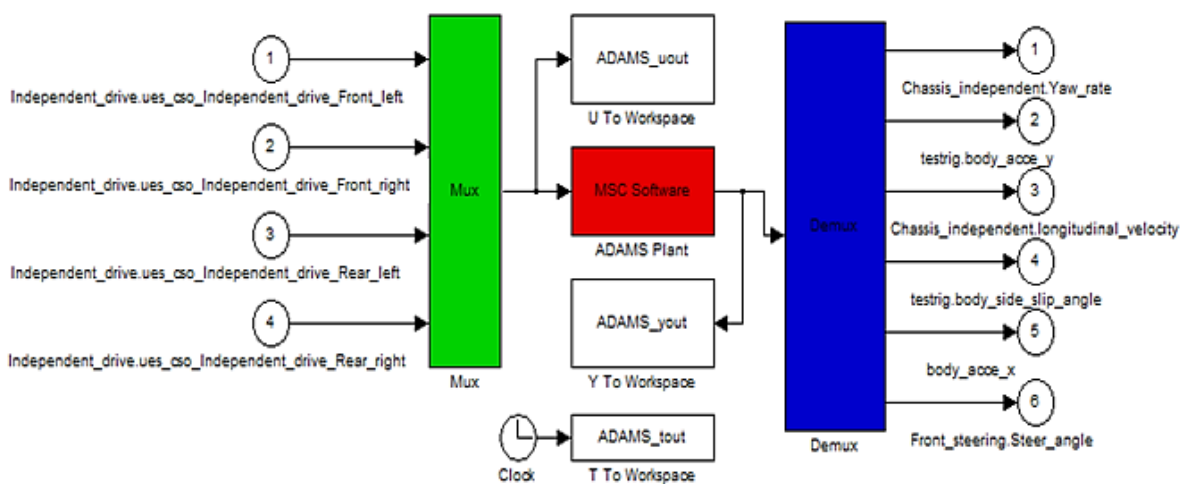

The Simulink model of the DYC is been shown in Figure 9.

Figure 9 Simulink model for DYC (see online version for colours)

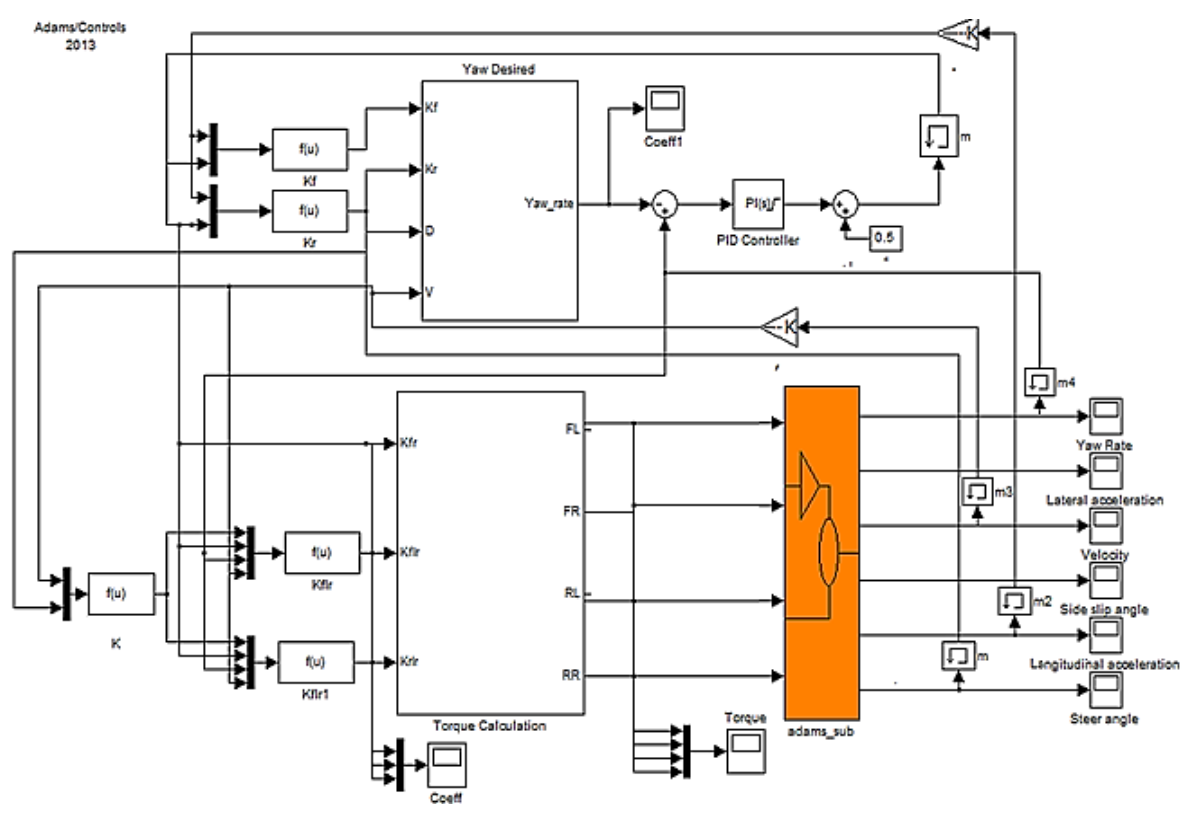

\section{Results}

The DYC model with side slip and yaw rate control applied to obtain zero side slip angle shows very promising results. There are number of models available in the literature for lateral stability control and side slip control of vehicles but most of them does not obtain closed form solution for these vehicle characteristics. 
This is a novel approach to get zero side slip angle by taking direct feedback from vehicle characteristics and using vehicle dynamics equations with simple PI control. The model is developed in such a way that it is capable to obtain different wheel torque requirements for a generic load case (accelerating/decelerating/cornering/combined load case). For investigation purpose, we have considered the vehicle undergoing standard ISO 3888 DLC manoeuvre. Figure 10 shows the vehicle undergoing DLC manoeuvre.

Figure 10 Vehicle undergoing DLC maneuver

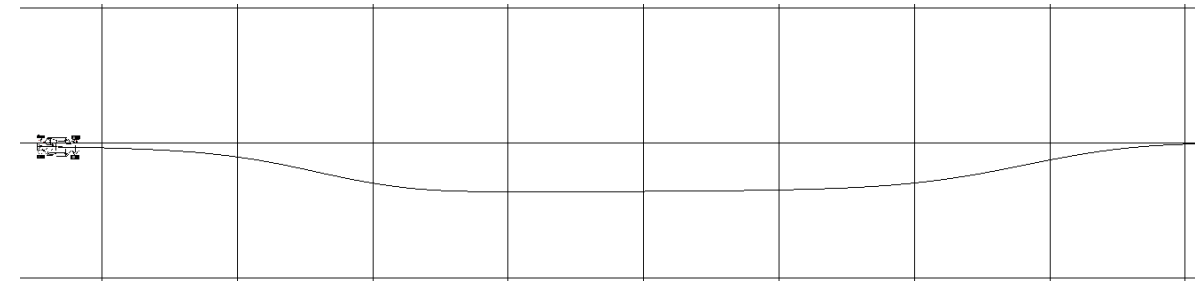

Figure 11 shows the desired and the observed yaw rate characteristics. The vehicle is made to follow the desired yaw characteristics by tuning the PI controller. For this purpose auto-tuning method is used to tune the control gains. In order to avoid wind-up of the controller an anti-windup clamping method is used. The observed yaw rate closely follows the desired value after number of tuning iterations.

Figure 11 Desired and observed yaw rate characteristics (see online version for colours)

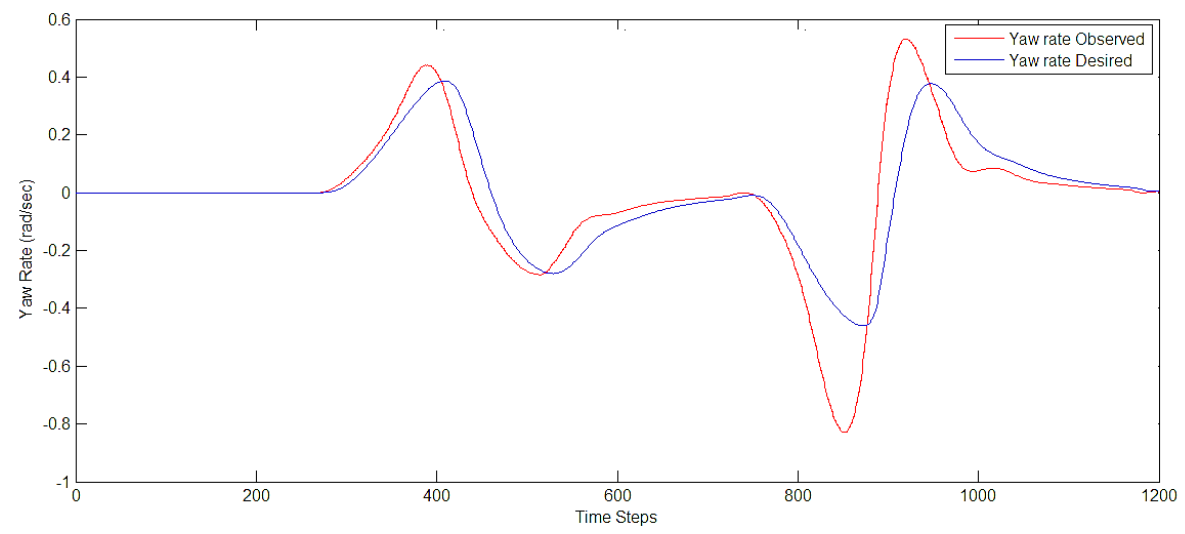

Figure 12 shows the vehicle velocity during lane change event at $72 \mathrm{kmph}$, i.e., $20 \mathrm{~m} / \mathrm{sec}$.

The maximum value of vehicle's lateral acceleration reaches up to 0.48 ' $\mathrm{g}$ ' during the test. Above plots shows the vehicle lateral and longitudinal accelerations.

The mathematical model for DYC was developed in order to achieve zero side slip. Below plot shows the side slip characteristics of the vehicle with and without DYC. It is clear from the plot that the control system works promisingly. The side slip angle is reduced a hundred times from a peak value of $1.35 \mathrm{deg}$ to $0.024 \mathrm{deg}$ (almost zero, the variation is because of various reasons discussed in Conclusions) which is less than about 56 times the original value before the DYC was applied. 
Figure 12 Vehicle velocity (see online version for colours)

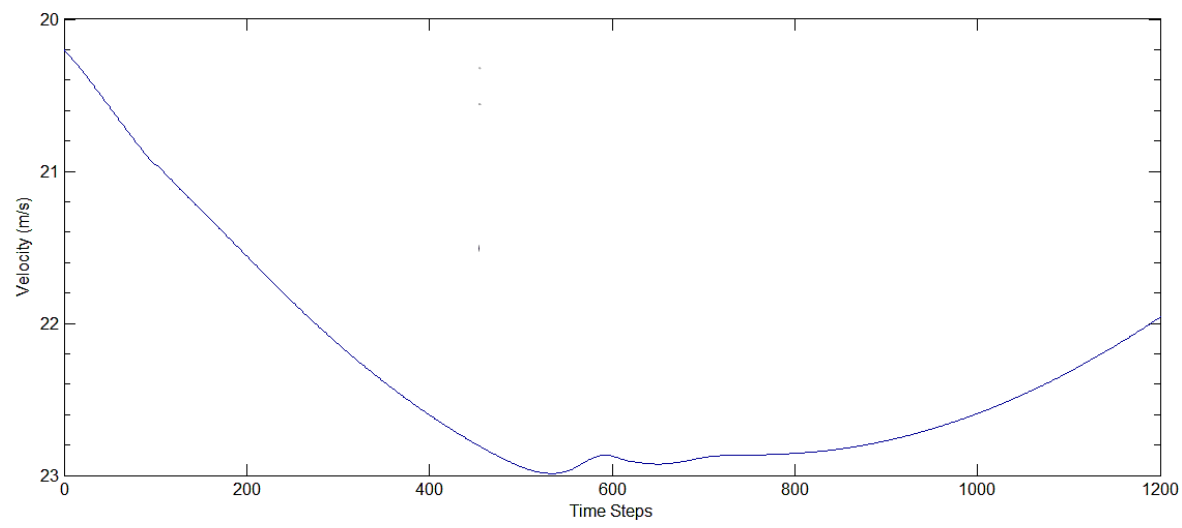

Figure 13 Vehicle lateral and longitudinal acceleration (see online version for colours)
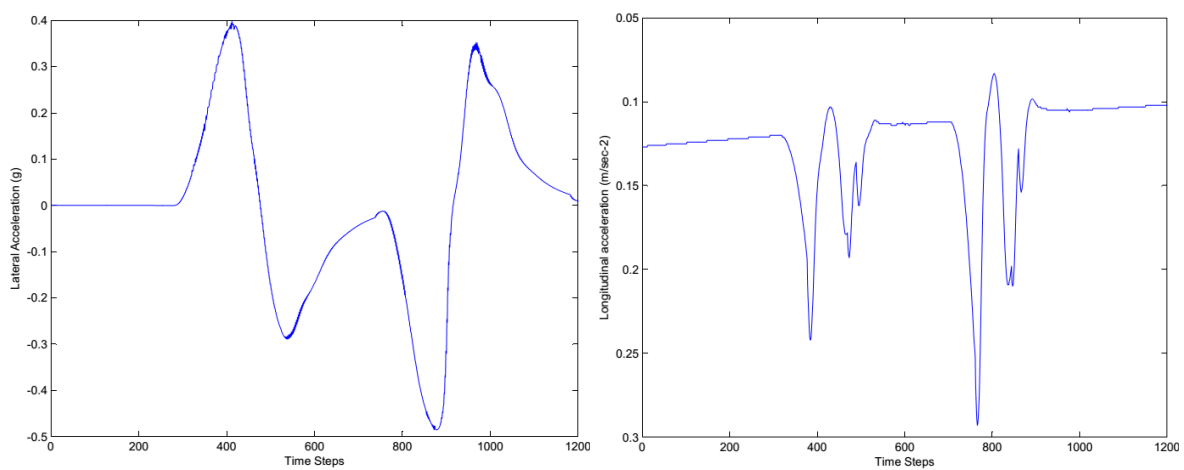

Figure 14 Vehicle side slip characteristics with and without DYC (see online version for colours)
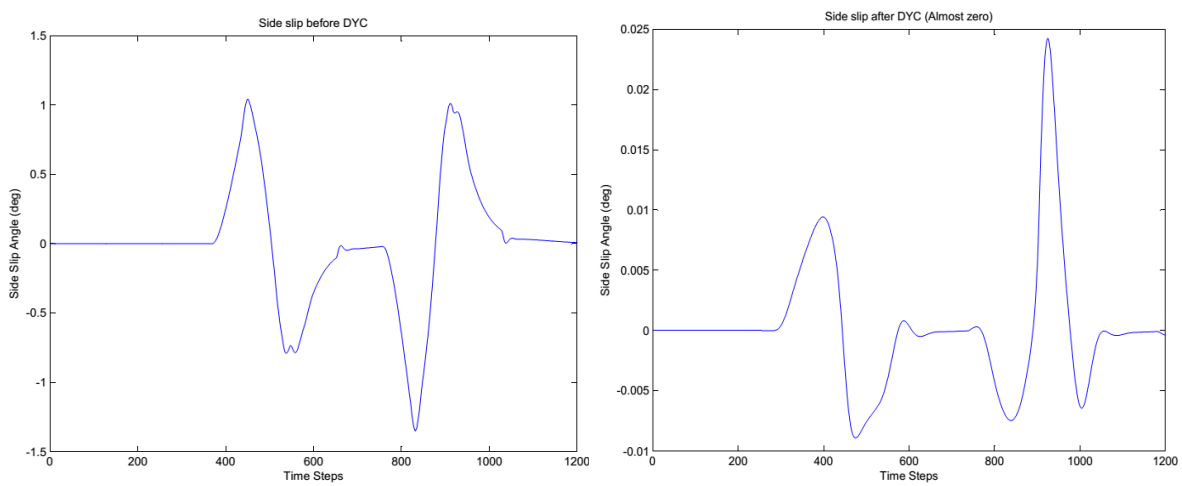

As discussed in the mathematical model above we have used three torque split ratios. These split ratios namely, $K_{f r}, K_{f l r}$ and $K_{r l r}$ are shown in the figure below. It is to be noted that initially a value of 0.5 is used for all of them so all the wheels have equal torque. As 
the vehicle accelerates and corners the ratios are varied so as to obtain the desired characteristics.

Figure 15 Torque split ratios (see online version for colours)

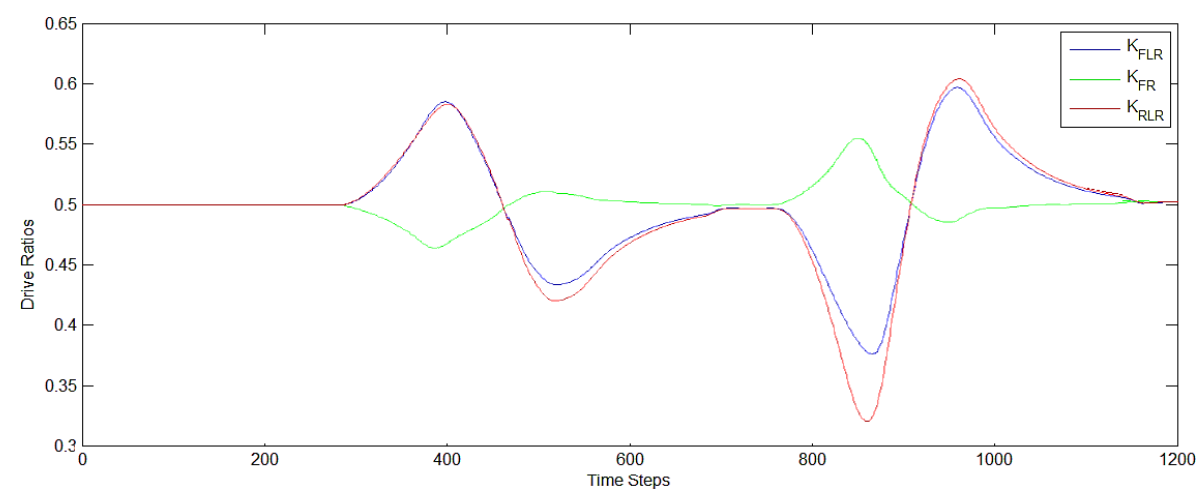

On the basis of these three torque split ratios, the four wheel torques have been accordingly calculated as:

$$
\begin{aligned}
& T_{f r}=n T K_{f r} K_{f l r} \\
& T_{f l}=n T K_{f r}\left(1-K_{f l r}\right) \\
& T_{r l}=n T\left(1-K_{f r}\right) K_{r l r} \\
& T_{r r}=n T\left(1-K_{f r}\right)\left(1-K_{r l r}\right)
\end{aligned}
$$

Here, $n$ is the total drive reduction ratio.

Figure 16 Four wheel torque distribution with time (see online version for colours)

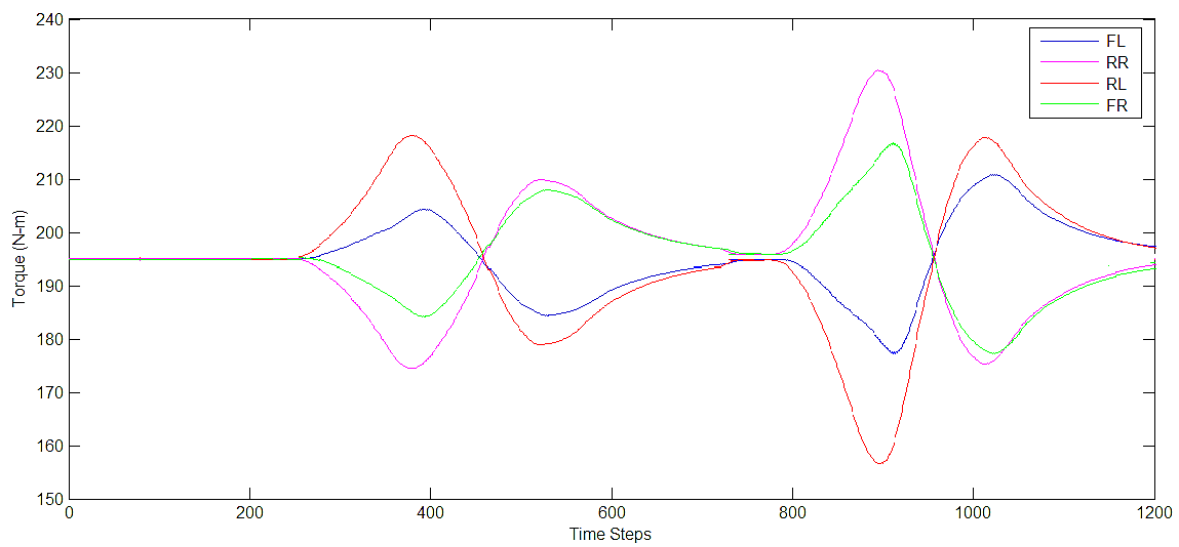


It is to be noted here that the torque distribution is in accordance with the in-hub wheel motor characteristics and the battery capacity. The motor maximum torque is $80 \mathrm{~N}-\mathrm{m}$. There is a drive reduction of 3.125 in motor hub itself. There is an additional reduction gear in the output shaft and the torque is further amplified by 2.25 . Initially, all the motors are set at an equal torque of $195 \mathrm{~N}$-m (i.e., 80*3.125). The motor torques have been varied such that the summation total torque do not exceed $195 * 4=780 \mathrm{~N}-\mathrm{m}$ (max battery output). Also, the maximum motor torque in accordance with motor capacity is limited to $250 \mathrm{~N}-\mathrm{m}$ (motor capacity) and the minimum is $120 \mathrm{~N}-\mathrm{m}$ (stalling torque).

\section{Conclusions and future scope}

This work was largely focused on implementing a DYC method for an independent four wheel driven vehicle. The model shows excellent results and we were able to have a better control on the lateral dynamics of the vehicle.

While developing the controller the energy consumption by the batteries and its optimisation has not been considered. This needs further research if one wants to operate in the optimum operating range of the batteries from cost effective and energy efficient point of view (Qian et al., 2010).

As discussed in the results section, we have not been capable to make side slip angle precisely equal to zero. The primary reason for that is that we have considered a planar vehicle model. The vehicle roll motions needs to be incorporated to build a sophisticated model. Also, two-dimensional road geometry is been used while in actual case the vehicle can go over a gradient along with road camber and other undulations. Therefore, a four wheel model needs to be developed instead of bicycle model. Also, in the scope of present research, we have only controlled two variables namely the yaw rate and the vehicle side slip angle. For future research with a combined roll-pitch-yaw vehicle model, we can develop a unified chassis controller capable of controlling roll and pitch motions.

\section{References}

Abe, M. (1999) 'Vehicle dynamics and control for improving handling and active safety: from four-wheel steering to direct yaw moment control', Proc. Inst. Mech. Eng., Part K: J. Multi-body Dynam., Vol. 213, No. 2, pp.87-101.

Abe, M. (2009) Vehicle Handling Dynamics, Butterworth-Heinemann, Oxford, UK.

Abe, M., Kano, Y., Suzuki, K., Shibahata, Y. and Furukawa, Y. (2001) 'Side-slip control to stabilize vehicle lateral motion by direct yaw moment', JSAE Rev., Vol. 22, No. 4, pp.413-419.

AVON (2013) [online] http://www.avontyres.es/ (accessed 26 August 2014).

Eslamian, M., Alizadeh, G. and Mirzaei, M. (2007) 'Optimization-based non-linear yaw moment control law for stabilizing vehicle lateral dynamics', Proc. IMech E Part D: J. Automob. Eng., Vol. 221, No. 12, pp.1513-1523

Esmailzadeh, E., Goodarzi, A. and Vossoughi, G.R. (2003) 'Optimal yaw moment control law for improved vehicle handling', J. Mechatron., Vol. 13, No. 7, pp.659-675.

Gutiérrez, J., Romo, J., González, M.I., Cañibano, E. and Merino, J.C. (2011) 'Control algorithm development for independent wheel torque distribution with 4 in-wheel electric motors', Fifth UKSim European Symposium on Computer Modeling and Simulation (EMS), pp.257-262. 
Kang, J., Yoo, J. and Yi, K. (2011) 'Driving control algorithm for maneuverability, lateral stability, and rollover prevention of $4 \mathrm{WD}$ electric vehicles with independently driven front and rear wheels', IEEE Transactions on Vehicular Technology, September, Vol. 60, No. 7, p.2987.

Kortüm, W. (1993) 'Review of multibody computer codes for vehicle system dynamics', Vehicle System Dynamics, Vol. 22, Sup. 1, pp.3-31.

Mirzaei, M., Alizadeh, G., Eslamian, M. and Azadi, Sh. (2008) 'An optimal approach to nonlinear control of vehicle yaw dynamics', Proc. IMechE Part I: J. Syst. Control Eng., Vol. 222, No. 4, pp.217-229.

Mokhiamar, O. and Abe, M. (2002) 'Effects of model response on model following type of combined lateral force and yaw moment control performance for active vehicle handling safety', JSAE Rev., Vol. 23, No. 4, pp.473-480.

MSC Software (2013) [online] http://www.mscsoftware.com/product/adams (accessed 26 August 2014).

Pacejka, H.B. (2002) Tyre and Vehicle Dynamics, Butterworth-Heinemann, Oxford, UK.

Park, K., Heo, S. and Baek, I. (2001) 'Controller design for improving lateral vehicle dynamic stability’, JSAE Rev., Vol. 22, No. 4, pp.481-486.

Qian, H., Xu, G., Yan, J., Lam, T.L., Xu, Y. and Xu, K. (2010) 'Energy management for fourwheel independent driving vehicle', International Conference on Intelligent Robots and Systems.

Rajamani, R. (2006) Vehicle Dynamics and Control, pp.15-47, Springer-Verlag, New York.

Selby, M., Manning, W.J., Brown, M.D. and Crolla, D.A. (2001) A Coordination Approach for DYC and Active Front Steering, SAE Technical Paper 2001-01-1275.

Shibahata, Y., Shimada, K. and Tomari, T. (1993) 'Improvement of vehicle maneuverability by direct yaw moment control', Vehicle Syst. Dynam., Vol. 22, No. 5, pp.465-481.

Spentzas, K.N. and Alkhazali, I. (2001) 'Generalisation of the concept of electronic differential', Forschung im Ingenieurwesen, Vol. 66, No. 6, pp.273-278, Springer-Verlag.

Tahami, F., Farhangi, S. and Kazemi, R. (2004) 'A fuzzy logic direct yaw-moment control system for all-wheel-drive electric vehicles', Vehicle System Dynamics, Vol. 41, No. 3, pp.203-221.

van Zanten, A., Erhardt, R., Landesfeind, K. and Pfaff, G. (1998) VDC System Development and Perspective, SAE Technical Paper 980235.

Wang, J. and Longoria, R.G. (2006) 'Coordinated vehicle dynamics control with control distribution', Proceedings of the 2006 American Control Conference, pp.5348-5353.

Yamakawa, J. and Watanabe, K. (2006) 'A method of optimal wheel torque determination for independent wheel drive vehicles', Journal of Terramechanics, Vol. 43, No. 3, pp.269-285.

Yoon, J., Yim, S., Cho, W., Koo, B. and Yi, K. (2010) 'Design of an unified chassis controller for rollover prevention, manoeuvrability and lateral stability', Vehicle System Dynamics: International Journal of Vehicle Mechanics and Mobility, Vol. 48, No. 11, pp.1247-1268, DOI: $10.1080 / 00423110903536403$.

Zheng, S., Tang, H., Han, Z. and Zhang, Y. (2006) 'Controller design for vehicle stability enhancement', Control Eng. Pract., Vol. 14, No. 12, pp.1413-1421. 


\section{Notations}

\begin{tabular}{|c|c|}
\hline$l_{f}$ & Distance from the centre of gravity to the front axle $(\mathrm{m})$ \\
\hline$l_{r}$ & Distance from the centre of gravity to the rear axle (m) \\
\hline$L$ & Distance between axles $(\mathrm{m})$ \\
\hline$W$ & Total weight of the vehicle $(\mathrm{kg})$ \\
\hline$h$ & Height of centre of gravity \\
\hline$v_{x}$ & Velocity in forward direction $(\mathrm{m} / \mathrm{s})$ \\
\hline$v_{y}$ & Velocity in lateral direction $(\mathrm{m} / \mathrm{s})$ \\
\hline$\Omega$ & Yaw rate $(\mathrm{rad} / \mathrm{s})$ \\
\hline$\beta$ & Vehicle side slip angle (rad) \\
\hline$\beta_{f 1 / 2}$ & Front wheel slip angle $(\mathrm{rad}) ; 1=$ left, $2=$ right \\
\hline$\beta_{r 1 / 2}$ & Rear wheel slip angle $(\mathrm{rad}) ; 1=$ left, $2=$ right \\
\hline$\alpha_{l / r}$ & Longitudinal slip left/right \\
\hline$K_{f / r 0}$ & Nominal cornering stiffness front/rear \\
\hline$K_{f 1 / 2}$ & Cornering stiffness, front tire left/right $(\mathrm{kN} / \mathrm{rad})$ \\
\hline$K_{r 1 / 2}$ & Cornering stiffness, rear tire left/right $(\mathrm{kN} / \mathrm{rad})$ \\
\hline$K_{\alpha}$ & Tire longitudinal force per unit slip \\
\hline$K_{f r}$ & Drive split ratio front/rear \\
\hline$K_{f l r}$ & Drive split ratio front left/right \\
\hline$K_{r l r}$ & Drive split ratio rear left/right \\
\hline$K_{\Omega}$ & Yaw moment coefficient \\
\hline$I_{i}$ & Moment of inertia, $\mathrm{i}=\mathrm{x}, \mathrm{y}, \mathrm{z}\left(\mathrm{mm}^{4}\right)$ \\
\hline$R_{w f f r}$ & Radius of wheel front/rear \\
\hline DYC & Direct yaw control \\
\hline$T$ & Total torque output of the batteries \\
\hline$d$ & Track width \\
\hline $4 \mathrm{WD}$ & Four wheel drive \\
\hline FAW & Front axle weight \\
\hline RAW & Rear axle weight \\
\hline
\end{tabular}

